\title{
Jogos do tempo e processos de identificação hegemonizados nos textos curriculares de História
}

Time games and hegemonized identification processes in the curricular texts of History

Carmen Teresa Gabriel ${ }^{\star}$

\section{Resumo}

As pesquisas em ensino de história tendem a evidenciar a importância das questões de temporalidade e de identidade para a reflexão sobre os processos de produção e de distribuição desse conhecimento. O professor de História é sistematicamente interpelado e convocado a contribuir para a construção e fixação de identidades por meio da mobilização de experiências (passado) e projetos (futuro), coletivos e individuais, selecionados como conteúdos a serem ensinados em cada presente. Em diálogo com as teorizações do discurso e os estudos narrativos, este texto tem por objetivo explorar os jogos do tempo que articulam passado, presente e futuro nas narrativas identitárias hegemonizadas nos Parâmetros Curriculares Nacionais de História que têm como leitor potencial o professor dessa disciplina.

Palavras-chave: narrativa histórica; teoria do discurso; textos curriculares.

\section{Abstract}

The researches on History teaching tend to show the importance of temporality and identity issues for reflection on the processes of production and distribution of this knowledge. The History teacher is systematically challenged and convoked to contribute with the construction and fixation of identities through the experiences of mobilization (past) and collective and individual projects (future) selected as contents to be taught in each present. In dialogue with the discourse theories and narrative studies, this paper aims to explore the time games that articulate past, present and future in hegemonized identity narratives in the National Curriculum Parameters of History which has as potential reader, the teacher of this discipline.

Keywords: historical narrative; discourse theory; curriculum texts.

\footnotetext{
* Doutora em Educação. Professora Titular de Currículo, Faculdade de Educação, Universidade Federal do Rio de Janeiro (UFRJ). Rio de Janeiro, RJ, Brasil. carmenteresagabriel@gmail.com
} 
As pesquisas em ensino de história dessas últimas três décadas tendem a evidenciar a importância das questões de temporalidade e de identidade para a reflexão sobre os processos de produção e de distribuição do conhecimento dessa área disciplinar. Essas questões, por sua vez, se encontram no epicentro das diferentes crises - "de historicidade", "da representação do real”, "de identidades", "da razão iluminista" - que marcam nossa contemporaneidade, deixando seus vestígios e efeitos no campo da História e nos interpelando como profissionais da área. Um abalo que se deu seja no lugar de pesquisador, seja no lugar de professor dessa disciplina escolar.

Em relação à questão temporal, expressões como "presentismo", "aceleração da História", "compressão da memória", "fim das utopias”, ou ainda "novas cartografias de espaço-tempo", em voga nos debates intelectuais da atualidade, são indícios dos efeitos performativos dessas crises nessa área de conhecimento. Do mesmo modo, os debates contemporâneos que trazem para a cena política a temática das "identidades múltiplas e fluídas e móveis" ou do "multiculturalismo" contribuem para desestabilizar o sentido unívoco e engessado de identidade nacional que o conhecimento histórico contribuiu, até data recente, para hegemonizar.

De maneira geral, essas crises, para além de suas especificidades ou apropriações teóricas e políticas, tendem a ter em comum o fato de emergirem em meio às fissuras de paradigmas deterministas e/ou metafísicos que se consolidaram ao longo da modernidade, radicalizando as críticas formuladas às leituras essencialistas do social.

Embora possa parecer paradoxal, a produção do conhecimento histórico não está imune a essas críticas. Como já venho questionando em outros trabalhos (Gabriel, 2013; 2015), se o entendimento de realidade como totalidade historicamente construída vem sendo utilizado como um álibi importante contra a denúncia de possíveis rasgos essencializantes nas análises do social, como continuar sustentando hoje essa definição, quando - no campo das teorizações sociais contemporâneas - as bases epistemológicas sobre as quais ela se pauta estão sendo questionadas? O que entender por historicidade quando algumas garantias acerca dos sentidos atribuídos à nossa orientação temporal são gravemente abaladas em nosso presente? Quando uma história tautológica, capaz de nos oferecer uma direção predeterminada do futuro, há muito tem 
sido criticada? Ou ainda, quando uma percepção do passado como algo que realmente aconteceu vem sendo problematizada?

Refiro-me particularmente às perspectivas teóricas pós-fundacionais que operam com a ideia de que qualquer significante, incluindo pois os termos realidade e história, se encontra em meio às disputas pelo preenchimento de seu sentido nos diversos contextos discursivos nos quais são mobilizados. Como significar realidade histórica em plena crise representacional que põe em xeque o sentido de linguagem fixada como reflexo ou espelho do mundo? (Gabriel, 2015). Como enfrentar os efeitos dessas crises no ensino de história sem problematizar categorias de análise como tempo e espaço, ontologicamente fundantes dessa área do conhecimento?

Este texto se inscreve nessa problemática, tendo como recorte privilegiado a questão da interface temporalidade-identidade tal como hegemonizada nos textos curriculares normativos, mais particularmente nos Parâmetros Nacionais Curriculares de História produzidos nos anos de 1990. Esse documento, apesar de datado, mantem sua atualidade na medida em que pode ser considerado como um evento discursivo na trajetória dessa disciplina escolar cujos efeitos ainda se fazem sentir em nosso presente.

Os Parâmetros Curriculares Nacionais de História (PCNs) podem ser vistos como uma tentativa de reposta a algumas das questões envolvendo os processos de definição da interface temporalidades-identidades no ensino dessa disciplina. Interessa-me assim analisar as potencialidades e limites desse enfrentamento. Meu propósito não é desqualificar essa ou outra tentativa, tampouco propor $a$ saída teórico-metodológica mais adequada para responder de forma satisfatória às questões anteriormente formuladas. Trata-se, neste texto, de continuar a fazer reverberar a seguinte questão: como pensar o ensino de uma História Nacional quando as noções de tempo e espaço que subjazem à narrativa de brasilidade hegemonizada ao longo da trajetória dessa disciplina escolar estão sendo questionadas?

Se as estratégias discursivas mobilizadas nos PCNs contribuem, sem dúvida, para desestabilizar a perspectiva temporal linear eurocêntrica, fortalecendo as críticas acumuladas à presença hegemônica da matriz historiográfica tradicional na produção do conhecimento histórico escolar, elas não oferecem, contudo, articulações temporais suficientemente potentes do ponto de vista teórico-didático para a passagem de uma linguagem de denúncia para uma 
linguagem de possibilidades. Essa passagem é, contudo, indispensável quando nos situamos no lugar da docência. Afinal, o professor de História é sistematicamente interpelado e convocado a contribuir para a construção e fixação de identidades por meio da mobilização de experiências (passado) e projetos (futuro) coletivos e individuais selecionados como conteúdos a serem ensinados em cada presente. ${ }^{1}$

A hipótese aqui sugerida consiste em afirmar que a efetivação do deslocamento de uma temporalidade linear de direção predeterminada para outras possibilidades de articulação entre passado, presente e futuro pode ser favorecida por uma mudança da postura epistêmica assumida na análise dos mecanismos mobilizados no processo de produção desse conhecimento escolar.

Sem pretensões de encontrar a resposta correta, este texto investe, pois, na potencialidade analítica de certas apostas teórico-políticas para o enfrentamento dessa questão. O que está em jogo é buscar pistas que permitam operar de forma simultânea e não hierarquizada com questões de ordem pedagógico-didática e epistemológicas que dizem respeito à natureza e à função social e política desse conhecimento disciplinar.

Os argumentos desenvolvidos foram organizados em duas seções. A primeira explicita a postura epistêmica assumida, destacando os diálogos estabelecidos com a Teoria do Discurso (Laclau; Mouffe, 2004; Marchart, 2009; Retamozo, 2009) e com os estudos narrativos (Ricoeur, 1997; Hartog, 1995, 2007; Dosse, 1999; 2001). Nesse âmbito da argumentação, busca-se igualmente sublinhar as contribuições dessa interlocução para fazer avançar algumas aporias e abrir pistas para uma linguagem das possibilidades. A segunda seção contextualiza a produção do documento curricular em tela, evidenciando as estratégias discursivas mobilizadas para sustentar a proposta de uma organização curricular na área de história diferente daquela até então hegemonizada. Retomo, assim, alguns fios da meada puxados naquela ocasião, em particular os que envolvem a tensão entre universal e particular, considerada como uma porta de entrada possível e produtiva para o enfrentamento das questões temporais e identitárias no âmbito dessa área disciplinar. 
ENSINO DE HISTÓRIA: ENTRE JOGOS DE LINGUAGEM E DO TEMPO

Os estudos e pesquisas (Gabriel, 2011; 2013; 2014; 2015; Oliveira; Gabriel, 2013; Gabriel; Monteiro, 2014) que vimos produzindo e desenvolvendo no GECCEH $^{2}$ têm procurado explorar o potencial heurístico para a análise do ensino de história da aproximação entre as categorias de análise discurso e narrativa, tais como formuladas respectivamente nas abordagens pós-fundacionais (Laclau; Mouffe, 2004; Laclau, 2005; Marchart, 2009) e no enfoque hermenêutico de Ricoeur (1997). Esse movimento não é sem riscos. Colocar para conversar autores que não operam no mesmo quadro de inteligibilidade, não investigam nos mesmos campos do conhecimento e tampouco compartilham os mesmos interesses de pesquisa, pode não ser produtivo e acarretar uma hibridização de frágil consistência teórica.

Atenta aos riscos e levando em consideração a complexidade e densidade dos respectivos referenciais teóricos, bem como o recorte privilegiado neste texto, interessa-me sublinhar, nesta seção, alguns argumentos da abordagem pós-fundacional que permitem destacar o potencial heurístico da categoria narrativa para a reflexão sobre a interface temporalidades-identidades em meio aos desafios colocados pelos efeitos da radicalização das críticas formuladas às perspectivas essencialistas que subjazem à historiografia escolar. Trata-se, pois, de explorar a articulação buscada entre os jogos da linguagem e os jogos do tempo (Gabriel; Costa, 2011; Gabriel, 2012; 2014) para a compreensão dos processos de produção e distribuição do conhecimento histórico legitimado e validado como objeto de ensino na educação básica.

Se é correto supor que os significantes discurso e narrativa tendem a remeter aos estudos da Linguística e/ou da Crítica Literária, a postura epistêmica aqui assumida autoriza, todavia, a mobilizá-los para além desses campos, permitindo reativar sob outras lentes teóricas a tensão universal e particular que perpassa os debates acadêmicos e as políticas curriculares e incidem diretamente nas questões de temporalidade e nos processos de identificação.

No que diz respeito ao significante discurso, como aponta Burity (2010), sua definição na pauta pós-fundacional extrapola o domínio da Linguística, abarcando a tessitura do social. Retamozo (2009) compartilha igualmente dessa leitura, salientando que o enfoque da Teoria do Discurso de Ernesto Laclau e Chantal Mouffe (2004) pode trazer para a reflexão, no campo das Ciências 
Sociais, a dimensão ontológica, até então restrita aos domínios da Filosofia. O que está em jogo é, portanto, a questão da possibilidade da definição/significação após a radicalização da crítica às perspectivas essencialistas.

Da perspectiva privilegiada por este texto, o significante discurso é que garante essa possibilidade. Ele é da ordem do material. Não se trata de questionar a materialidade do mundo, mas sim de reconhecer a impossibilidade de seu acesso imediato - isto é, do acesso feito sem a mediação da linguagem. Essa, por sua vez, é vista como constituinte da realidade, cumprindo pois uma função que extrapola à de representação de algo cuja existência se definiria fora de seu campo, na medida em que seu significado estaria depositado em alguma essência ou fundamento metafísico. Em vez de operar com significantes de positividade plena, com identidades de sentidos unívocos e estabilizados para todo o sempre, a Teoria do Discurso reconhece a diferença como ponto de partida das análises do social. Diferença, heterogeneidade, dispersão, multiplicidade são termos que se articulam para dar conta do Social ${ }^{3}$ que é o pano de fundo no qual nos movimentamos e produzimos sentidos para nossos movimentos.

A produção do discurso é sempre uma tentativa de regulação dessa dispersão. Sem pontos de articulação ou direção predefinidos, as estruturas e os sujeitos são produzidos discursivamente na provisoriedade de toda contingência. Afirmar, como o faz Laclau (2005), que toda configuração social é discursiva, significa dizer que os sentidos que produzimos e as formas com que nos relacionamos com e no mundo se explicam somente em meio aos jogos da linguagem.

Discurso é assim o significante usado para nomear qualquer totalidade estruturada contingencialmente por meio de duas lógicas - a da equivalência e a da diferença - que operam de forma relacional. A primeira atua de maneira a estabelecer uma cadeia equivalencial entre distintas unidades diferenciais. A segunda intervém no sentido de romper com o processo de equivalência mobilizado pela primeira, que tende a ser infinito. Esse rompimento produz um limite radical, uma fronteira, expelindo para fora da cadeia o antagônico, o Outro, que passa a funcionar como seu "exterior constitutivo". O estabelecimento de um corte radical e a produção desse antagônico é o que caracteriza qualquer processo de significação. Impossível e necessário, o ato de significar é, pois, condição para acessar a materialidade do mundo e agirmos politicamente. 
Esse entendimento de discurso redimensiona o debate teórico-político sobre a tensão entre universal e particular que tem ocupado um lugar de destaque no enfrentamento das crises que interpelam a educação básica em nosso tempo presente. Nessa abordagem discursiva, o universal não é visto como solução, tampouco como problema, mas sim como condição de pensamento e de produção de sentidos. Esse significante assume uma dimensão política estratégica, na medida em que exerce uma função discursiva que passa a ser objeto de disputas em qualquer processo de significação. Um significante particular que ocupe o lugar do universal em um determinado contexto discursivo significa a consolidação de um processo de hegemonização. Afinal, nesse enfoque, hegemonizar é a universalização de um sentido particular. É, pois, aquilo pelo qual todos lutamos, na medida em que, sem hegemonização, ainda que sempre provisória, de nossos interesses particulares (sejam eles individuais ou do grupo com o qual nos identificamos), não há possibilidade de efetivar processos de significação; não há possibilidade de formular demandas, não há possibilidade da própria luta política.

Desse modo, combater posições hegemônicas significa produzir outras hegemonizações. A luta política é assim uma luta para sedimentar, estabilizar hegemonias, isto é, uma luta para fazer esquecer o momento contingente de todo processo de significação.

Importa assim, em vez de investirmos na superação da tensão universal e particular, explorarmos as disputas pela definição da própria fronteira que a define. Dito de outra maneira, superar aqui significa fazer trabalhar a aporia que carrega a tensão entre necessidade e impossibilidade de qualquer processo de definição, não como uma impossibilidade sem lugar próprio, mas sim como uma impossibilidade positiva com função discursiva na constituição do social. Essa ressignificação nos oferece, do ponto de vista teórico-metodológico, a possibilidade de operarmos na tensão, não mais por escolha, mas como a própria condição do pensamento.

O exercício teórico que temos procurado desenvolver nas nossas pesquisas em ensino de história consiste justamente em explorar os efeitos dessa perspectiva pós-fundacional para pensar as disputas pelos processos de significação que se entrecruzam na produção desse campo de conhecimento. Neste texto, concentramos a análise nos termos tempo histórico e identidade nacional, percebidos como significantes flutuantes em torno do quais se acirram as 
disputas pela definição hegemônica de história do Brasil ensinada na educação básica.

Esse enfoque autoriza a operar com o entendimento de temporalidade enquanto a forma singular como o conhecimento histórico entra no debate identitário. Tal afirmação pressupõe, todavia, incorporarmos em nossa análise as contribuições teóricas dos estudos narrativos, em particular a categoria de análise narrativa histórica, tal como formulada na hermenêutica de Paul Ricoeur (1997).

Afinal, narrar, como nos ensina Ricoeur (1997), é atribuir um significado a nossa (individual e coletiva) experiência no tempo. Ao (nos) narrarmos, realizamos uma síntese do heterogêneo, articulando, a partir de cada presente, passados e futuros. Não narramos experiências que vivenciamos fora da linguagem. Toda experiência já é linguagem, já está no domínio da narração. Toda narrativa é uma estrutura temporal. Um currículo de História seleciona, reorganiza, articula múltiplas narrativas, produzindo outras sínteses do heterogêneo que disputam a legitimidade na cultura escolar.

Nessa perspectiva, a narrativa histórica - como estrutura temporal que organiza a dispersão de nossas experiências - é intensamente mobilizada nas políticas de identidade e de diferença por meio de dispositivos variados que acionam memórias, produzem silêncios, lembranças e esquecimentos. Nos processos de identificação, passados são escolhidos, registrados, arquivados, reativados, transmitidos para reatualizar tradições inventadas e comunidades nacionais imaginadas. Nesse mesmo movimento, um outro no tempo e no espaço é produzido, seja como exemplo a ser seguido, seja como meta a ser atingida - ou seja até mesmo como um antagônico das identidades narrativas que se quer reafirmar. Seguir seus traços, trazê-lo para o presente, transformá-lo em objeto de investigação ou do ensino são ações recorrentes das práticas profissionais de pesquisadores e professores de História.

Se retomarmos as críticas endereçadas à matriz historiográfica escolar qualificada como tradicional, é possível destacar alguns aspectos que reforçam a pertinência da aposta teórica aqui pretendida. Não é por acaso que desde os anos 1980 diferentes matrizes historiográficas reelaboradas e hibridizadas no âmbito da cultura escolar, apesar de operarem com ênfases e abordagens diferenciadas na reflexão sobre as questões de tempo e de identidade, tenham em comum o fato de explicitarem seu distanciamento frente ao que tem sido 
cunhado como história tradicional - que assume, nos discursos da área, o lugar da matriz-outra antagônica, fonte de todos os males. O significante tradicional, utilizado muitas vezes para adjetivar procedimentos de pesquisa, conteúdos de ensino-aprendizagem, práticas docentes, tem significado na área de ensino de história tudo aquilo que se quer combater.

Desde então, as múltiplas propostas e implementações de reformas curriculares dessa área disciplinar emergem em meio a um movimento pendular - e aparentemente contraditório - que oscila entre o acirramento da crítica à matriz tradicional e a reativação de dispositivos que reforçam sua sedimentação. De modo geral, essas propostas insistem na necessidade de se pensar os processos de produção e organização do conhecimento histórico escolar a partir de diálogos com matrizes historiográficas - estruturalismo marxista, École des Annales, história cultural, história das mentalidades - que se distanciam da perspectiva positivista - com o intuito de atender tanto às exigências pedagógicas internas ao processo de didatização quanto às demandas políticas mais amplas que atravessam o nosso presente.

Propostas de organização dos saberes históricos por eixos temáticos, história temática ou história integrada são exemplos desse movimento de busca por matrizes alternativas da historiografia escolar que procuram deslocar os sentidos hegemônicos de tempo histórico e de identidade nacional mobilizados pela história tradicional. Estudos recentes (Araujo, 2010; Gabriel, 2014) apontam contudo que, embora com variações e alguns reajustes, essa perspectiva tradicional se mantém poderosa e de difícil desestabilização, no âmbito da historiografia escolar.

No que se refere à questão da temporalidade, a crítica formulada ao ensino de história tradicional se concentra no questionamento da perspectiva do tempo linear eurocêntrico monocultural (Santos, 2006) em torno da qual se estruturou e se hegemonizou uma forma de organização curricular particular. É essa noção particular de temporalidade pautada na ideia de linearidade com direção preestabelecida que ocupa o lugar do universal, permitindo a fixação hegemônica de um sentido de processo histórico. O desafio consiste, pois, em simultaneamente sustentar essa crítica e formular uma proposta de organização curricular alternativa que seja capaz de garantir que a história ensinada não se fragmente no processo de transposição didática, impossibilitando a sua pressuposta compreensão narrativa. 
Até segunda ordem, a crítica endereçada a uma articulação específica entre universal e particular na definição do tempo histórico não pressupõe a recusa de toda possibilidade de se pensar outras articulações possíveis entre passado, presente e futuro. Noutras palavras: ela não almeja fechar a noção de processo histórico, comprometendo assim a ideia de totalidade temporal que lhe é própria. No entanto, a problematização da temporalidade linear eurocêntrica de fato desestabiliza a visão de processo, fixada hegemonicamente como sinônimo de progresso, localizado em um futuro a ser alcançado mediante o cumprimento de etapas a serem superadas umas após as outras. Ainda que em algumas versões o progresso seja substituído pela ideia de se produzir uma ordem social menos desigual, mais justa, a visão de um futuro promissor de contornos previamente delineados - como sendo o objetivo a ser alancado pelas sociedades - permanece com força, imprimindo o sentido da orientação temporal da história ensinada na educação básica.

Caberia assim questionar se o que está em jogo é a própria noção de processo ou de um sentido particular desse significante universalizado na matriz tradicional. O reconhecimento da estrutura narrativa do conhecimento histórico como categoria de análise permite responder a essa questão pela escolha da segunda alternativa. Entendida como síntese do heterogêneo, a narrativa regula e organiza as diferentes experiências individuais e coletivas passadas, presentes e futuras, em uma trama a ser ensinada. Dito de outra maneira, a aversão a uma história narrativa - cujas objeções vêm se acumulando desde os anos trinta do século passado - traduz a crítica formulada a um sentido particular hegemonizado de narrativa, mas não implica a negação da estrutura narrativa desse conhecimento. Afinal narrar significa não perder o fio da meada.

Em termos das questões relacionadas aos processos de identificação, o que tem sido problematizado é a articulação direta do ensino de história com a produção de uma narrativa nacional hegemônica em torno da construção do Estado nacional que tende a negar a pluralidade etnocultural da sociedade brasileira. As críticas se endereçam à centralidade atribuída a uma forma de entendimento de lealdade nacional na produção do conhecimento histórico escolar. Essa centralidade tem sido questionada em função de mudanças substantivas e epistemológicas que caracterizam a virada do século XX para o século XXI. Com efeito, em meio à intensificação de movimentos sociais e à 
instauração da crise paradigmática, a ideia de uma identidade nacional como elemento central da constituição do sujeito da modernidade passa a ser questionada abrindo possibilidades de se repensar outros processos de identificação e reativar assim a tensão universal vs. particular inscrita na problemática identitária.

No plano das políticas curriculares na área de História, a reativação dessa tensão tem pressionado as fronteiras que definem os sentidos do significante nacional que adjetiva a história legitimada a ser ensinada na educação básica. A crítica à hegemonia dessa marca de lealdade, bem como à implosão dos movimentos culturais não pressupõe, no entanto, necessariamente a impossibilidade de produção de toda e qualquer história do Brasil. O que está sendo colocado em xeque é um sentido hegemônico do nacional, uma fronteira estabelecida entre nós e outros fixada nos currículos de História do Brasil. Aqui também a categoria narrativa histórica abre pistas para se pensar outras articulações entre universal e particular que possam oferecer saídas para que as histórias nacionais permaneçam um recorte potente do ponto de vista político em meio às demandas de nosso tempo.

A seguir ensaio uma análise discursiva dos PCNs, evidenciando as formas hegemonizadas nesse texto curricular para o enfrentamento dos desafios mencionados. Importa sublinhar que, como em todo texto político dessa natureza, sua escrita traduz a negociação possível entre as diferentes vozes e demandas envolvidas, formuladas por sujeitos posicionados de forma diferenciada nas relações de poder daquele contexto. As fragilidades e ambiguidades analisadas nesse texto foram objeto de debates acirrados entre os sujeitos que participaram diretamente em sua produção, como tive oportunidade de explorar em outra ocasião (Gabriel, 2003).

A intenção aqui é retomar algumas constatações da análise realizada naquele momento sob as lentes da abordagem discursiva pós-fundacional, tendo como foco o recorte privilegiado. Nunca é demais sublinhar que essa é apenas mais uma leitura possível dos PCNs de História, sem a menor pretensão, pois, de ser exclusiva ou a mais acertada. Sua pertinência e contribuição devem ser avaliadas à luz do recorte e dos referenciais teóricos aqui privilegiados. 


\section{ARTiCUlaÇões ENTRE TEMPORALIDADE E IDENTIDADE NOS PCNS DE HisTóRIA}

Nesse diálogo, tem permanecido principalmente o papel da História em difundir e consolidar identidades no tempo, sejam étnicas, culturais, religiosas, de classes e grupos, de Estado ou Nação. (PCN de História, 1998, p.29, grifo meu)

A releitura desse documento quase vinte anos depois de sua implementação confirma a sua atualidade e força performativa. As questões sobre tempo histórico e identidade nacional problematizadas nesse documento traduziram não apenas os ares daquele presente, mas também e principalmente representaram o fim da inocência da historiografia escolar. Como sustentar a pertinência de uma história escolar tradicional ${ }^{4}$ depois das críticas que lhe foram endereçadas naquele documento? Como continuar acreditando na neutralidade política de uma história nacional ensinada nas escolas?

Fim da inocência e também início de uma busca e de disputas permanentes por outras matrizes historiográficas capazes de hegemonizar, na cultura escolar, outros sentidos de temporalidades e identidades. Desde então, a disputa na fronteira do que é e do que não é história ensinada legitimada e validada para ser ensinada na educação básica continua viva, aberta, à espera da hegemonização de outras possíveis suturas.

Se por um lado o quadro teórico aqui privilegiado autoriza a compreender que as lutas pela "signifixação" (Leite, 2010) de história ensinada são definidoras do próprio jogo político, por outro lado ele aponta igualmente para a necessidade de fechamentos provisórios, capazes de produzir outras hegemonias e antagonismos. Como anteriormente explicitado, esses fechamentos de sentido são impossíveis no sentido de previamente definidos e /ou definitivamente estáveis ou sedimentados, mas simultaneamente necessários na contingência de cada presente.

A força performativa dos PCNs, cujos efeitos se fazem sentir até hoje, está na tentativa de deslocar a fronteira hegemônica até então definidora do conhecimento histórico escolar. Sua fragilidade foi não ter conseguido propor um outro significante tão potente, capaz de articular as diferentes demandas e ocupar o lugar do hegemônico deixado vazio pela desestabilização da história 
tradicional. Esse vácuo instaurado pelos PCNs talvez seja um dos fatores explicativos da presença forte de certos traços dessa matriz histórica que se quer negar mas que volta e meia fazem erupção nos debates atuais. Essa matriz resiste, se reatualiza e está sempre à espreita para retomar seu lugar de outrora.

A compreensão dessa forma de inserção do PCN no jogo político da década de 1990 pressupõe análise dos mecanismos acionados para a mobilização de algumas cadeias de equivalência definidoras de conhecimento histórico escolar em detrimento de outras.

O PCN de História pertence a um presente cujas características permitem articulações singulares entre os múltiplos processos de significação mobilizados na produção de um texto dessa natureza. O presente em questão - a década de 1990 - apresentava características específicas que podem ser identificadas por meio das marcas textuais desse documento. Com efeito, o desenvolvimento da pressão dos movimentos sociais que emergem na cena política brasileira a partir da década de 1980, os debates e avanços internos aos campos da Educação e da História, os questionamentos trazidos pela crise da modernidade a partir da segunda metade do século passado contribuíram para a construção do campo de possibilidades no qual foram negociadas essas articulações.

Selecionei como textos curriculares para tratamento empírico os PCNs de História de $5^{\mathrm{a}}$ a $8^{\mathrm{a}}$ séries (terceiro e quarto ciclo do ensino fundamental), focalizando na análise a forma como a articulação entre os significantes tempo histórico e identidade nacional foi acionada. Que sentidos de tempo e de identidade foram mobilizados para dar conta da produção de uma narrativa da brasilidade? Que contextos discursivos - academia, escola, cenário político mais amplo - foram privilegiados como produtores de sentidos desses significantes? Como esse texto curricular opera com a tensão entre universal e particular que atravessa os processos de significação da interface temporalidade-identidade nos quais ele investe e para cuja fixação ele contribui?

Nota-se que esse texto curricular de história emerge em meio a questões políticas que o extrapolam e que desde o início colocam em xeque sua própria relevância e pertinência. Afinal, qual o sentido de se investir em um currículo de pretensões nacionais em uma sociedade multicultural e desigual? Essa questão atravessa o documento e está na base da ambiguidade do lugar atribuído à História do Brasil nessa proposta curricular, como explorarei mais adiante. 
A primeira observação a ser destacada no que concerme à produção e fixação do sentido de história a ser ensinado nos PCNs diz respeito à função discursiva atribuída à matriz historiográfica dita tradicional. Apesar da falta de consenso por parte dos elaboradores, consultores e pareceristas sobre a concepção de história a ser privilegiada (Gabriel, 2003), alguns traços textuais dessa proposta curricular apontam para um acordo quanto à matriz teórica que não devia mais servir de referencial para o ensino da disciplina. A grande vilã, responsável pela obsolescência do saber histórico escolar e contra a qual tem se insurgido a comunidade disciplinar dessa área, desde a década de 1980, continuava sendo, sem sombras de dúvidas, a história tradicional.

Embora não haja um trecho específico onde a negação da matriz tradicional apareça claramente expressa, ela se encontra espalhada ao longo das partes que compõem os PCNs de História, sendo passível de ser detectada por diferentes marcas textuais. Na segunda seção da primeira parte por exemplo - "O conhecimento histórico: característica e importância social” (PCN de História, 1998, p.29-37) - esse posicionamento contra a história tradicional traduz-se pela ausência de qualquer referência a essa matriz, entre as inúmeras concepções historiográficas atuais consideradas passíveis de servirem de referência para os saberes escolares e, consequentemente, para a elaboração de propostas curriculares.

A segunda observação diz respeito justamente à forma como a interface identidade-temporalidade é mobilizada, para sustentar o processo de demonização da história tradicional. No que se refere à temporalidade, a posição contra essa matriz manifesta-se por meio da tentativa de fixação de outros sentidos de tempo histórico, em oposição àquele fixado como hegemônico naquela perspectiva: "No caso do tempo histórico de uma tradição marcada por datas alusivas a sujeitos e fatos passa-se a enfatizar diferentes níveis e ritmos de durações temporais" (ibidem, p.39, grifos meus).

Percebe-se claramente a incorporação das matrizes historiográficas francesas, em particular as diretamente relacionadas à École des Annales. A noção de temporalidades múltiplas é incorporada nessa proposta curricular como estratégia para deslocar a noção de linearidade eurocêntrica, abrindo pistas para se pensar outros sentidos possíveis para o significante processo histórico.

É esse mesmo movimento de aversão à temporalidade linear que permite, nesse documento, expelir igualmente da cadeia equivalencial definidora da 
história ensinada a matriz historiográfica marxista. Apesar de se distanciar da matriz tradicional, essa matriz passa a compor a cadeia definidora antagônica, isto é, a da história-outra que se quer combater. A história marxista - que emerge com força nos anos 1980 como alternativa para a história narrativa tradicional - torna-se, assim, também alvo das críticas nesse documento. A rejeição a essa matriz aparece a reboque da crítica da concepção do tempo linear, direcionada em um primeiro momento à história tradicional. Com efeito, é perceptível no texto curricular analisado a tentativa de negação dessa concepção. Associada a uma linearidade condenável e/ou a uma perspectiva totalizante que, a partir da década de 1990, passa a ser, segundo os formuladores dessa proposta curricular, igualmente reprovável, a história marxista como matriz historiográfica de referência para o saber escolar tende, nos anos 1990, a deixar de ser uma concorrente de peso na disputa pela hegemonia nesse campo disciplinar.

A despeito das razões apontadas, essa rejeição implícita e/ou explícita, traduz uma forma de lidar com a tensão universal e particular no âmbito dessa disciplina. Percebe-se que a crítica à noção de processo como sinônimo de progresso tende a assumir o lugar da crítica a toda e qualquer perspectiva totalizante do tempo histórico. A negação da concepção marxista como matriz histórica referencial para o saber histórico escolar - assimilada portanto ao grupo das "teorias globalizantes" - abre espaço a fim de se incluir, no leque de alternativas possíveis de saber de referência para a história ensinada, outras matrizes relacionadas a um domínio historiográfico mais difuso, associado àquele que ficou conhecido como História Cultural.

Como deixa entrever o debate conceitual em torno do termo identidade presente nesse documento, são incorporadas as consequências epistemológicas da crise das grandes narrativas e da pulverização da identidade monolítica moderna. Nesse movimento, algumas matrizes históricas vão sendo classificadas como obsoletas enquanto outras passam a ser consideradas atuais, férteis, e responsáveis pela orientação para a produção de um "bom" texto do saber de "história a ensinar".

Em relação à temática da identidade nacional, esse documento produz e fixa determinadas articulações que mobilizam diretamente a tensão universal e particular. Interessante observar que o significante nacional que adjetiva o termo identidade tende a se enfraquecer, deixando lugar para a incorporação 
de múltiplas identidades na historiografia escolar. A pertinência do uso desse significante oscila: ora é empregado para reafirmar a importância de se incluir a narrativa nacional na cadeia hegemônica da história a ser ensinada; ora é apenas uma marca de lealdade identitária entre as demais, ora equivale aos demais termos que significam a história a ser combatida.

Essa oscilação do sentido atribuído ao termo nacional está diretamente relacionada à dificuldade, nesse documento, em atribuir de maneira inequívoca ao ensino da História do Brasil um lugar central no currículo da disciplina. Em diferentes passagens desse documento, percebe-se uma intencionalidade expressa em priorizar o ensino de uma história nacional, sinalizando que a superação de uma visão eurocêntrica no âmbito da historiografia escolar ainda representa um problema não resolvido. Do mesmo modo é possível identificar trechos em que a prioridade dada ao ensino da História do Brasil perde sua força; ela passa a ser apenas sugerida, recomendada, pressuposta ou assumida de forma velada e contraditória.

Essa indefinição quanto ao lugar assumido pela história do Brasil se torna mais perceptível quando se trata de abordar no documento a reelaboração didática de uma história nacional outra, que possa dar conta das demandas políticas e epistemológicas do presente no qual essa proposta é formulada. Com efeito, na última seção da primeira parte - "Conteúdos de História: critérios e seleção" (ibidem, p.45-48) - e na totalidade da segunda parte desse documento (p.53-101), incluindo a seção intitulada "Orientações e métodos didáticos" (p.77-101), a própria escolha de trabalhar com eixos temáticos, bem como as temáticas selecionadas e as orientações metodológicas propostas, dão indícios mais da intencionalidade dos autores de se afastarem da história tradicional do que de apresentarem alternativas didáticas para se pensar outras articulações temporais e outros sentidos de nação nas aulas de História do Brasil. Ao longo de todo o documento, o combate à história tradicional se faz presente como condição indispensável para superar a didatização de narrativas nacionais:

E seus conteúdos deveriam enfatizar as tradições do passado homogêneo de lutas pela defesa do território e de unidade nacional e os feitos gloriosos de personagens identificados com ideais republicano. É no contexto do final do século XIX que são construídos alguns mitos da História brasileira, presentes até hoje no 
ensino (bandeirantes como Raposo Tavares e Borba Gato, militares como Duque de Caxias, mártires como Tiradentes). (ibidem, p.21, grifo meu)

De modo semelhante, na segunda parte do documento, que corresponde à operacionalização da proposta a partir da identificação e explicitação dos objetivos, conteúdos e estratégias didáticas selecionados, o ensino da História do Brasil não aparece como prioritário. Ao justificarem os critérios de organização e de seleção dos conteúdos ainda na primeira parte do documento (ibidem, p.46), os/as autores/as não incluem nenhum critério explícito que traduza a intencionalidade em priorizar o ensino da História do Brasil:

Os conteúdos expressam três grandes intenções: contribuir para a formação intelectual e cultural dos estudantes; favorecer o conhecimento de diversas sociedades historicamente constituídas, por meio de estudos que considerem múltiplas temporalidades, e propiciar a compreensão de que as histórias individuais e coletivas se integram e fazem parte dessa história. (PCNs, 1998, p.46)

A ausência de objetivos explícitos relativos à História do Brasil para o terceiro (ibidem, p.54) e quarto ciclos (ibidem, p.66) é outro exemplo dessa fragilidade da assunção da pertinência de uma História do Brasil. Importa salientar que, para o terceiro ciclo, dos sete objetivos identificados, apenas um - "conhecer realidades históricas singulares, distinguindo diferentes modos de convivência nelas existentes" (ibidem, p.54) - pode ser articulado ao saber histórico de dimensão declarativa - isto é, o saber que pressupõe a transposição de informações, conteúdos cognitivos específicos, embora não associado particularmente à História do Brasil. Quanto ao quarto ciclo, dos nove objetivos explicitados, apenas dois podem ser classificados na categoria de saberes declarativos: "conhecer as principais características do processo de formação e das dinâmicas dos Estados Nacionais" e "identificar e analisar lutas sociais, guerras e revoluções na História do Brasil e do mundo" (ibidem, p.66). Somente esse último faz uma referência explícita à história nacional.

Essa ambivalência emerge com força no momento da definição dos conteúdos da História do Brasil a serem ensinados no terceiro e quarto ciclos, o que evidencia problemas de ordem didática relativos ao processo de textualização. 
Interessa-me explorar mais de perto como a narrativa nacional é proposta enquanto objeto de ensino-aprendizagem nesse documento curricular. Que elementos são acionados quando se trata de transpor a(s) intriga(s) em torno da construção da narrativa da nossa história nacional?

Selecionei como ponto de partida da análise a eventual transposição didática de um acontecimento específico - a Independência do Brasil -, considerado um evento discursivo clássico da narrativa nacional produzida pela historiografia escolar hegemônica. Foi pois a partir dessa variável de uma intriga maior em torno da qual se tece a narrativa da nação brasileira que procurei compreender como foram resolvidas no PCN de História algumas das tensões inerentes à natureza do saber histórico, em particular a tensão entre universal e particular, que envolve as dimensões temporal e identitária.

Como reelaborar, adequar uma História do Brasil aos moldes dos eixos temáticos? Que critérios adotar para a seleção e delimitação dos saberes escolares? Que acontecimentos, sujeitos, conceitos, durações privilegiar na estrutura narrativa da História do Brasil que se quer legitimar nesse documento? Como conciliar pensamento crítico e necessidade de memória, de um passado comum, indispensáveis para a construção da identidade narrativa do brasileiro? Como os significantes nacional e processo histórico se articulam e se hegemonizam na opção dos eixos temáticos? Essas questões tornam-se mais pertinentes quando se evidencia as dificuldades encontradas na adequação interna à dinâmica dessa esfera de didatização da concepção braudeliana de tempo histórico.

O exercício de análise proposto em torno do acontecimento Independência do Brasil permite constatar que a proposição de um tipo de relação a ser estabelecida com um passado nacional a ser preservado, ainda que de forma crítica, quando associada à ideia de eixos temáticos e à noção de tempo braudeliano, torna-se difícil de ser operacionalizada do ponto de vista didático nos limites desse documento curricular.

Tal como estruturado, esse documento oferece possibilidades contraditórias de tratamento didático da interface identidade nacional/temporalidades. São muitas as varáveis que justificariam essa afirmação, como por exemplo: a ênfase nas perspectivas culturalistas na escolha da abordagem historiográfica, o tratamento didático do tempo braudeliano, a escassez de informações sobre o significado de eixo temático, bem como a concepção de autonomia recente 
privilegiada nesse documento. Considerando os limites deste texto, centrei o foco da análise empírica no tratamento didático dispensado, nesse documento curricular, à interface eixo temático - múltiplas temporalidades.

A proposta de eixos temáticos como possibilidade de reelaboração didática do saber histórico aponta para alguns avanços importantes no ensino da disciplina. Ao incluir as contribuições de ordem teórica-metodológica de algumas matrizes historiográficas defensoras da cientificidade desse saber, ela oferece pistas relevantes para se pensar as dimensões explicativa e reflexiva, bem como a necessária inserção desse conhecimento no domínio do verdadeiro, indispensável para sua validação como objeto de ensino. A atenção dispensada ao trabalho com as fontes históricas e aos procedimentos de pesquisa histórica em geral, presente nesse texto curricular, é uma contribuição importante para a mudança da relação estabelecida com o passado. No entanto, a maneira de lidar com a tensão universal e particular nas estratégias discursivas acionadas para se enfrentar a complexidade do processo de reelaboração didática do saber histórico, ao minimizar a importância da dimensão narrativa nas lutas pela significação desse conhecimento, enfraquece a potencialidade transformadora da proposta, tanto no plano político como no pedagógico.

A dificuldade da didatização do conhecimento histórico na lógica das múltiplas temporalidades se manifesta já pelo modo como as discussões teóricas correlatas são introduzidas no documento. $\mathrm{O}$ debate acadêmico em torno dessa temática é apresentado em uma seção à parte, tal como um apêndice, ao final do documento (ibidem, p.96-101), desvinculado portanto textualmente da parte do documento onde são abordadas as questões relativas à seletividade política e cultural e à delimitação epistemológica do saber histórico escolar.

A consequência pedagógica mais imediata da organização do saber escolar nos moldes de eixos temáticos e das múltiplas temporalidades é que, da forma como eles estão apresentados, dificultam o fortalecimento da inteligibilidade narrativa própria desse saber, deixando aberta e sob a responsabilidade do docente a necessidade de se produzir outras narrativas de brasilidade. Afinal como afirma o documento:

Esta é uma opção do ensino de História que privilegia a autonomia e a reflexão do professor na escolha dos conteúdos e métodos de ensino. É igualmente uma concepção metodológica de ensino de História que incentiva o docente a criar intervenções pedagógicas significativas para a aprendizagem dos estudantes e 
que valoriza reflexões sobre as relações que a História, principalmente a História do Brasil, estabelece com a realidade social vivida pelo aluno. (PCN, 1998, p.47)

Retomemos o exemplo da Independência do Brasil para continuar a análise pretendida.

Dentre as possibilidades de leitura que o documento oferece, se apresenta como a de mais difícil operacionalização a de recolocar esse acontecimento em uma trama mais ampla, representada pelos eixos temáticos, abrindo assim pistas para se pensar em outros sentidos de processo histórico e articulações temporais entre passado, presente e futuro, a fim de se favorecer a produção de uma narrativa nacional outra.

O risco de essa proposta reforçar a concepção temporal que ela própria combate está presente sobretudo devido à ausência de explicitação de outras opções de reelaboração didática. Duas outras possibilidades se apresentam, ambas tendendo, por razões diferentes, seja a reafirmar o sentido hegemônico do significante processo - como fatos que se encadeiam em uma sequência temporal linear -, seja a esvaziar o ensino de história de sua dimensão temporal. A primeira, por uma atitude de prudência ou acomodação muito comum na docência, que consiste em fazermos o que nós conhecermos e o que nos ensinaram. A segunda, por uma leitura possível dos usos do tempo braudeliano que não me parece a mais produtiva.

Esse evento tem seu lugar, nessa proposta curricular, em diferentes partes do documento. Por exemplo, ele pode ser entendido como uma das proposições de conteúdos do subtema "Nações, povos, lutas, guerras e revoluções", ou como um dos desdobramentos possíveis do eixo temático proposto para o quarto ciclo - "História das Representações e das Relações de Poder". Ou ainda, como complemento da proposta de conteúdos para se trabalhar os subtemas: "Diferenças e semelhanças, transformações e permanências entre formas de organização dos Estados Nacionais, confrontos, lutas guerras e revoluções, procurando sintetizar os estudos realizados" ou "Estudos das relações presente-passado sobre as organizações políticas, a constituição dos Estados Nacionais, as representações e os mitos construídos para as nações, os ideais nacionalistas e os confrontos políticos internacionais" (PCNs de História, 1998, p.72). 
No entanto, o desdobramento didático da operacionalização da concepção privilegiada da interface tempo-identidade, no momento da explicitação da seleção de eixos temáticos, conteúdos e procedimentos, limita-se a enfatizar a necessidade de se trabalhar as permanências e mudanças, correndo-se assim o risco de se reduzir a "história a ser ensinada" a um grande quadro comparativo entre sociedades e tempos plurais, a partir do qual é possível estabelecer semelhanças e diferenças. Dessa forma, o aluno pode aprender a diferença entre o Estado nacional brasileiro e um outro qualquer, mas sem saber, caso o professor não tenha a preocupação de ensiná-las, as particularidades históricas que constituem nosso campo de experiência e que abrem possibilidades de se pensar a nossa utopia. Em nenhum momento do documento aparece, no plano textual, preocupação em costurar os conteúdos ou as temáticas nacionais em uma trama maior. Nem mesmo nos critérios de avaliação essa exigência se faz presente.

Abre-se assim a possibilidade de uma configuração narrativa da história nacional fragmentada, segundo a qual o Sete de Setembro é visto como um conteúdo facultativo da "História das Representações e das Relações de Poder". Não como um dos ingredientes indispensáveis da trama do processo de Independência, lugar de memória privilegiado para se pensar uma das articulações alternativas para o "estar sendo brasileiro", em função das questões colocadas pelo nosso presente. Essa análise se sustenta mesmo quando analisamos a forma como esse evento é citado: ao modo de uma sugestão de conteúdos. Como deixa entrever a passagem abaixo, o fato de termos como processo, nação, independência política serem citados como conteúdos possíveis, não garante o sentido a ser atribuído a cada um desses significantes, tampouco o lugar atribuído ao terceiro na produção da narrativa nacional.

Processo de constituição do território, da nação e do Estado brasileiro, confrontos, lutas, guerras e revoluções, que incluíam administração política colonial, coroa portuguesa no Brasil, Independência política, Estado Monárquico, Estado Republicano, alianças e políticas internacionais no Império e na República, o Estado brasileiro e suas alianças políticas e econômicas regionais ... lutas pela independência política, processo político de independência do Brasil, guerras provinciais (Confederação do Equador, Guerra dos Farrapos etc.)... (PCN, 1998, p.69) 
Na perspectiva teórica aqui privilegiada, pensar o ensino da História não se limita a pensar na seleção de tramas a se narrar; é necessário também pensar modos de se transpor a estrutura narrativa inerente a esse tipo de saber para a esfera de seu ensino. Não basta negarmos um tipo de narrativa em bloco como, por exemplo, o da história tradicional, pautada em estratégias de transposição já experimentadas e legitimadas até data relativamente recente no âmbito da comunidade disciplinar -, sem oferecer alternativas para a reelaboração do saber histórico escolar a partir de outras articulações temporais. Dito de outra forma: superar uma matriz narrativa no âmbito da historiografia escolar pressupõe ir além da seleção de uma ou mais matrizes historiográficas em disputa na academia.

Se o PCN de História permite pensar os eixos temáticos como estratégia discursiva potente para superar matrizes históricas consideradas obsoletas, ou para limitar quantitativamente o volume de conteúdos históricos passíveis de serem ensinados, não fica esclarecido, contudo, como essa modalidade de organização temporal dos conteúdos pode dar conta da complexidade da natureza epistemológica da história. Ficam em aberto questões importantes, por exemplo: como os eixos temáticos podem se articular à estrutura narrativa inerente a esse conhecimento? A que eles correspondem em termos de delimitação do saber? Em que medida os eixos temáticos equacionam a tensão específica do saber histórico escolar entre a necessária reorganização do saber e sua estrutura narrativa, que pressupõe a preservação de uma noção de processo sem a qual não é possível ensinar história?

Essas questões continuam a ecoar em nosso presente. Seu enfrentamento é mais que urgente se não quisermos colocar em risco a pertinência política de ensinarmos a singularidade de nosso processo histórico em meio às disputas contemporâneas. O PCN de História contribui para inaugurar um caminho importante que continua a ser trilhado por pesquisadores e professores de História. Nesse movimento, a tensão entre o que não mais fazer e o que é possível fazer como alternativa passa a ser objeto de disputas no campo da didática e da formação docente nessa área disciplinar. O papel do professor da educação básica nessas disputas é fundamental à condição todavia de que a defesa da autonomia de seu trabalho não signifique um fazer espontâneo que possa dispensar sua formação profissional. 


\section{REFERÊNCIAS}

ARAUJO, Cinthia. Ensino de história e as relações de colonialidade nos processos de construção da identidade nacional In: ENCONTRO NACIONAL DE DIDÁTICA E PRÁTICA DE ENSINO, XV, 2010, Belo Horizonte. Convergências e tensões no campo da formação e do trabalho docente: políticas e práticas educacionais, 2010.

BRASIL. Ministério da Educação. Parâmetros Curriculares Nacionais de História. Brasília, 1998.

BURITY, Joanildo. Teoria do discurso e educação: reconstruindo vínculo entre cultura e política. Teias [online], n.22, p.1-23, 2010.

DOSSE, François. A História à prova do tempo: da História em migalhas ao resgate do sentido. São Paulo: Ed. Unesp, 2001.

A História em migalhas: dos Annales à Nova História. São Paulo: Ensaio; Campinas: Ed. Unicamp, 1992.

GABRIEL, Carmen Teresa. Currículo de história: entre experiências temporais e espaciais. In: ZAMBONI, E.; GALZERANI, M. C.; PACIEVITCH (Org.) Memória, sensibilidades e saberes. São Paulo: Alínea, 2015.

Memórias e projetos de Brasil validados no ensino médio: narrativas nacionais em disputa nos textos curriculares. In: LEITE, M. S.; GABRIEL, C. T. (Org.) Linguagem, discurso, pesquisa e educação. 1.ed. Petrópolis: DePetrus; Faperj, 2014. v.1, p.252-280.

. Que passados e futuros circulam nas escolas de nosso presente? In: GONÇALVES, Marcia de Almeida; MONTEIRO, Ana Maria; REZNIK, Luís; ROCHA, Helenice (Org.) Qual o valor da história hoje? Rio de Janeiro: Ed. FGV, 2011.

. Teoria da história, didática da história e narrativa: diálogos com Paul Ricoeur. Revista Brasileira de História, São Paulo: Anpuh, v.32, n.64, p.187-210, dez. 2012.

Um objeto de ensino chamado História: a disciplina de História nas tramas da didatização. Tese (Doutorado em Educação) - Programa de Pós-Graduação em Educação, Pontifícia Universidade Católica do Rio de Janeiro (PUC-Rio). Rio de Janeiro, 2003.

GABRIEL, Carmen Teresa; COSTA, Warley. Currículo de história, política da diferença e hegemonia: diálogos possíveis. Educação e Realidade, Porto Alegre, v.36, n.1, p.127-146, jan./abr. 2011.

GABRIEL, Carmen Teresa; MONTEIRO, Ana Maria F. C. Currículo de história e narrativa: desafios epistemológicos e apostas políticas. In: MONTEIRO, Ana Maria et al. Pesquisa em ensino de história: entre desafios epistemológicos e apostas políticas. Rio de Janeiro: Faperj; Mauad X, 2014. p.23-40. 
HARTOG, François. L'art du récit historique. In: BOUTIER, Jean; JULIA, Dominique (Ed.) Passés recomposés: champs et chantiers de l'histoire, Paris: Autrement, 1995. p.184-193. (Série Mutations, n.150/151).

. Tempos do mundo, História, escrita da História. In: GUIMARÃES, Manoel Luiz Salgado (Org.) Estudos sobre escrita da História. Rio de Janeiro, Sete Letras, 2007.

LACLAU, Ernesto. La razón populista. Buenos Aires: Fondo de Cultura Económica, 2005.

LACLAU, Ernesto; MOUFFE, Chantal. Hegemonía y estratégia socialista: hacia una radicalización de la democracia. Buenos Aires: Fondo de Cultura Económica, 2004.

LEITE, Miriam Soares. Adolescência e juventude no ensino fundamental: signifixações no contexto da prática curricular. Teias, v.11, n.22, p.55-74, maio/ago. 2010.

MARCHART, Olivier. El pensamento político pós-fundacional: la diferencia política en Nancy, Lefort, Badiou y Laclau. Buenos Aires: Fondo de Cultura Económica, 2009.

OLIVEIRA, Talita M. C. R.; GABRIEL, Carmen Teresa. Ensino de História e a invenção do comum: tensões identitárias em diferentes escalas na política curricular do MERCOSUL educacional. Práxis Educativa, Ponta Grossa, v.8, n.2, jul./dez. 2013.

RETAMOZO, Martin. Lo político y la politica: los sujetos político, conformacíon y disputa por el orden social. Revista Mexicana de Ciencias Políticas y Sociales, México, v.51, n.206, 2009.

RICOEUR, Paul. Tempo e narrativa. Campinas: Papirus, 1997. 3v.

SANTOS, Boaventura de Sousa. A gramática do tempo: para uma nova cultura política. São Paulo: Cortez, 2006.

\section{NOTAS}

${ }^{1}$ Cumpre destacar que essa afirmação faz referência à superfície textual das propostas curriculares. Isso significa que nada impede que essa passagem se efetive na prática docente cotidiana a despeito dos textos curriculares adotados.

${ }^{2}$ Grupo de Estudos Currículo, Cultura e Ensino de Historia (GECCEH), vinculado ao Núcleo de Estudos de Currículo (NEC/UFRJ) sob minha coordenação, no qual desenvolvemos estudos na área de Currículo tendo como foco a abordagem discursiva da interface conhecimento, cultura, poder. Este texto está diretamente vinculado à pesquisa atualmente em curso - "Abordagens discursivas de juventude no tempo presente: questões metodológicas nas análises de textos curriculares" (2013-2015) - com apoio do CNPq (Bolsista de produtividade). 
${ }^{3}$ A maiúscula é um recurso gráfico utilizado por alguns autores pós-fundacionais para nomear o social entendido como uma instância indefinida que é simultaneamente condição e impossibilidade da ordem social.

${ }^{4}$ As críticas à matriz historiográfica tradicional datam dos anos 1980, como é possível constatar no conjunto de propostas curriculares que emergem naquela década. No entanto, o fato de os PCNs operarem com uma escala de abrangência nacional permitiu o acirramento do combate travado contra essa concepção historiográfica.

Artigo recebido em 28 de setembro de 2015. Aprovado em 23 de novembro de 2015. 